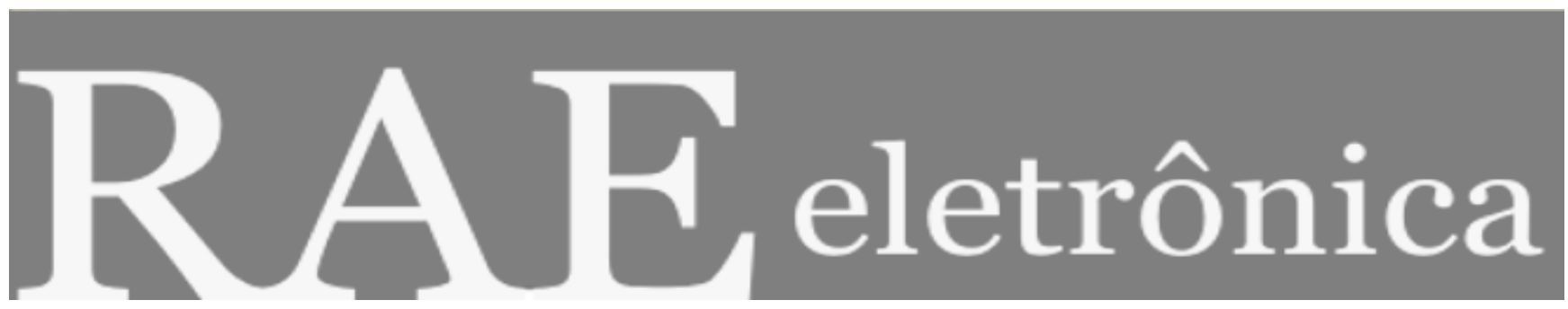

\title{
IMPACTOS DA PRIVATIZAÇÃO SOBRE AS ESTRATÉGIAS COMPETITIVAS DE EMPRESAS DE PETRÓLEO: UM ESTUDO DE CASOS
}

Por:

\section{Jorge Manoel Teixeira Carneiro Jorge Ferreira da Silva Maria Alice Deschamps Ferreira Cavalcanti}

RAE-eletrônica, v. 2, n. 2, jul-dez/2003.

http://www.rae.com.br/eletronica/index.cfm?FuseAction=Artigo\&ID=1395\&Secao=ESTRATÉGIA\& Volume $=2 \&$ Numero $=2 \& A n o=2003$

CCopyright, 2002, RAE-eletrônica. Todos os direitos, inclusive de tradução, são reservados. É permitido citar parte de artigos sem autorização prévia desde que seja identificada a fonte. A reprodução total de artigos é proibida. Os artigos só devem ser usados para uso pessoal e nãocomercial. Em caso de dúvidas, consulte a redação: redacao@rae.com.br.

A RAE-eletrônica é a revista on-line da FGV-EAESP, totalmente aberta e criada com o objetivo de agilizar a veiculação de trabalhos inéditos. Lançada em janeiro de 2002, com perfil acadêmico, é dedicada a professores, pesquisadores e estudantes. Para mais informações consulte o site www.rae.com.br/eletronica.

RAE-eletrônica

ISSN 1676-5648

(C)2002 Editora: Fundação Getulio Vargas - Escola de Administração de Empresas de São Paulo.

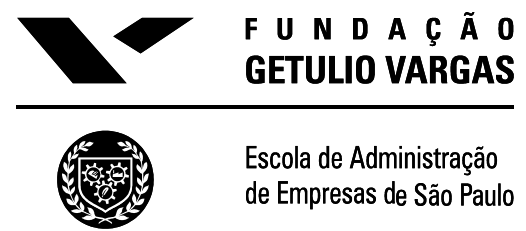




\title{
IMPACTOS DA PRIVATIZAÇÃO SOBRE AS ESTRATÉGIAS COMPETITIVAS DE EMPRESAS DE PETRÓLEO: UM ESTUDO DE CASOS
}

\section{Jorge Manoel Teixeira Carneiro}

Professor da PUC-Rio. Mestre em Administração de Empresas pela PUC-Rio.

E-mail: jorgemtc@admin.puc-rio.br

Endereço: Rua Dezenove de Fevereiro, 127/201 - Botafogo - Rio de Janeiro- RJ, 22280-030.

Interesses de pesquisa: Estratégia de empresas, negócios internacionais.

\section{Jorge Ferreira da Silva}

Professor da PUC-Rio. Doutor em Engenharia Industrial pela PUC-Rio.

E-mail: shopshop@iag.puc-rio.br

Endereço: Rua Marquês de São Vicente, 225 - Gávea - Rio de Janeiro - RJ, 22453-900.

Interesses de pesquisa: Estratégia de empresas, estratégias colaborativas.

\section{Maria Alice Deschamps Ferreira Cavalcanti}

Mestre em Administração de Empresas pela PUC-Rio. Gerente Executiva da Petrobrás.

E-mail: deschamps@petrobras.com.br

Endereço: Av. Chile, $6520^{\circ}$. andar - Centro - Rio de Janeiro - RJ, 20035-900.

Interesses de pesquisa: Estratégia de empresas.

\section{RESUMO}

Em diversos países, o processo de desregulamentação da indústria do petróleo tem chegado até a privatização das empresas. Como conseqüência, o ambiente competitivo se torna mais hostil. A mudança no controle das empresas, associada às mudanças no ambiente competitivo, têm provocado alterações significativas nas estratégias competitivas adotadas. As empresas que antes não apresentavam estratégias competitivas claras, passam a exibir padrões de estratégias de diferenciação, ao mesmo tempo em que buscam paridade de custos com os demais concorrentes. Os dados da presente pesquisa sugerem que as tipologias estratégicas de Porter (1980) e de Mintzberg (1988) seriam adequadas à classificação das estratégias das empresas de petróleo, com destaque para a primeira, em função da parcimônia e da unicidade de tipo estratégico (i.e., cada empresa pôde ser classificada em um, e apenas um, dos tipos estratégicos do modelo) e destaque para a segunda em função do maior nível de detalhamento e poder descritivo.

\begin{abstract}
In several country the deregulation of the oil \& gas industry has led to privatization of the former state-owned companies. As a result, the competitive environment has become more hostile. The change of ownership, together with modification in the competitive environment, have caused significant modifications in the competitive strategies. While companies did not use to have clear competitive strategies, after privatization they start to show clear patterns of differentiation strategies while at the same time they seek cost parity in the industry. The present research indicates that Porter's (1980) and Mintzberg's (1988) typology seem to be appropriate to classify oil companies' strategies. Porter's typology has two point in its favor: it is more parsimonious and if exhibits uniqueness of strategic type (i.e., each company would be classified in one, and only one, category of the model). On the other hand, Mintzberg's typology offers greater detail and descriptive power.
\end{abstract}




\section{PALAVRAS-CHAVE}

Estratégias competitivas, estratégias de mercado, vantagem competitiva, petróleo \& gás. KEYOWRDS

Competitive strategies, market strategies, competitive advantage, oil \& gas. 


\section{INTRODUÇÃO}

As últimas duas décadas têm se caracterizado por um discurso favorável à diminuição da interferência do Estado na gestão das empresas e nos processos microeconômicos. A desregulamentação que vem sendo observada em diversas indústrias acaba conduzindo, em boa parte dos casos, à privatização das empresas estatais.

$\mathrm{Na}$ indústria do petróleo, a privatização representa uma reversão dos processos de nacionalização ocorridos no início do século, os quais foram decorrentes do avanço do pensamento comunista e da reestruturação das economias após as duas Guerras Mundiais.

As empresas privatizadas, antes habituadas a um ambiente previsível - monopolista ou extremamente regulado - se vêm frente a frente com os desafios e oportunidades do aumento da competição. Em conseqüência, estas empresas modificam sua atitude e postura com relação ao mercado e à concorrência, de forma a se adaptarem ao novo ambiente.

Esta pesquisa ganha relevância no contexto da América Latina pelo fato de alguns países do continente (Argentina, Bolívia e Peru) já terem privatizado suas estatais de petróleo, enquanto outros (por exemplo, Brasil, Chile e Venezuela) vêm modificando consideravelmente o arcabouço regulatório da indústria.

A eventual verificação de que existe um referencial teórico, já validado em diversas outras indústrias, que também seja apropriado à classificação e análise das estratégias das empresas da indústria do petróleo no presente contexto de transformação de setor é relevante tanto para os executivos, quanto para legisladores e agentes reguladores, pois permitirá que os impactos das decisões (sejam elas decisões de negócio ou de legislação) sejam avaliados em função das mudanças nas posições competitivas das empresas.

Esta pesquisa apresenta dois principais objetivos:

1) Sob o ponto de vista das empresas (ex-)estatais selecionadas, descrever, em dois intervalos temporais (antes e depois da privatização): (a) a estrutura da indústria, (b) as estratégias competitivas.

2) Analisar, de forma parcial e simplificada, a aplicabilidade das tipologias de estratégias genéricas de Porter (1980) e de Mintzberg (1988) para a classificação das estratégias de empresas (especificamente, as empresas de petróleo) em contexto de significativa alteração do arcabouço regulatório.

Na seção Metodologia são detalhadas as limitações da pesquisa que somente permitem uma análise parcial e simplificada.

\section{ESTRUTURA DA INDÚSTRIA, ESTRATÉGIAS COMPETITIVAS E DESEMPENHO}

Porter (1980, 1985) entende que a estrutura da indústria determina a natureza da competição e a natureza da competição é um determinante significativo do desempenho das empresas. A estratégia influencia o desempenho, tanto de uma forma direta, quanto indiretamente através da influência sobre a estrutura da indústria (Figura 1). Nesta pesquisa a Estrutura da Indústria foi operacionalizada a partir do Modelo das Cinco Forças de Porter (1980) (Figura 2). 


\section{Figura 1 - Perspectiva de Porter}

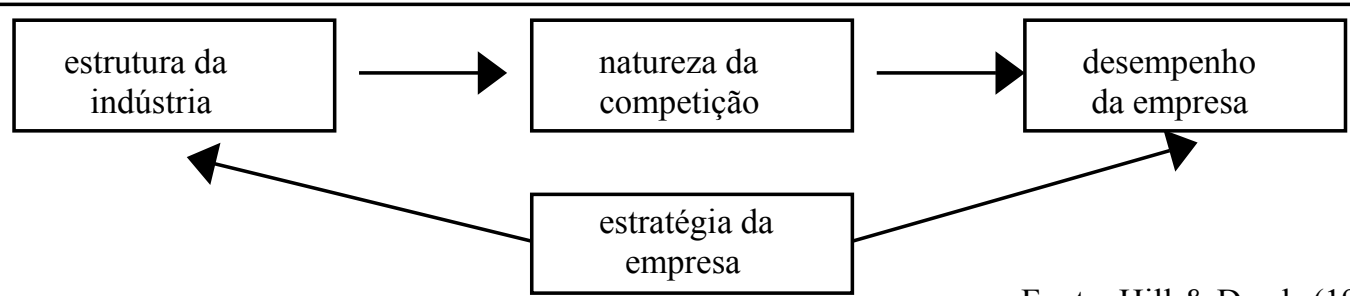

Fonte: Hill \& Deeds (1996)

\section{Figura 2 - Elementos da Estrutura da Indústria (Porter, 1980)}

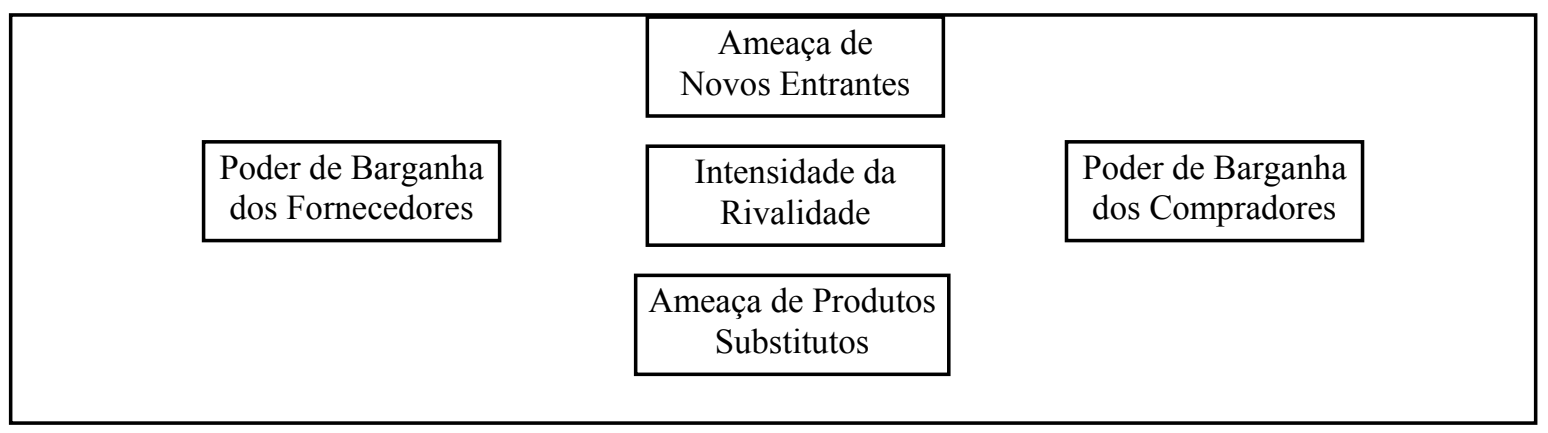

\section{ESTRATÉGIAS COMPETITIVAS}

O conceito de estratégias (ditas) genéricas advém do fato de que alguns autores (por exemplo: Hambrick, 1983a; Miles et al., 1978; Mintzberg, 1988; Porter, 1980, 1985) acreditam ser possível definir-se uma tipologia de estratégias suficientemente amplas de tal forma que elas sejam aplicáveis a qualquer empresa, em qualquer tipo de indústria e em qualquer estágio de desenvolvimento da indústria (Herbert \& Deresky, 1987). Ou dito de outra forma, poderia ser identificado um número limitado de arquétipos estratégicos que capturariam a essência das diversas posturas competitivas da maioria das empresas (Hambrick, 1983b).

Nesta pesquisa foram utilizadas duas tipologias de estratégias genéricas: a tipologia de Porter (1980) e a tipologia de Mintzberg (1988).

\section{Estratégias Genéricas de Porter (1980)}

Porter $(1980,1985)$ propôs uma tipologia composta por três estratégias genéricas (Figura 3): liderança no custo total, diferenciação e enfoque. Segundo Porter, as empresas que apresentariam melhor desempenho seriam aquelas que conseguissem aplicar uma, e apenas uma, das três estratégias genéricas. As empresas que procurassem uma estratégia híbrida ou que fracassassem na busca por uma das três estratégias foram por ele designadas como stuck-in-the-middle (expressão traduzida para o Português como meio-termo). $\mathrm{O}$ fato de uma empresa ser classificada no meio-termo não significa que ela não emprega métodos e armas competitivas típicas de uma ou mais das estratégias genéricas, mas apenas que a sua estratégia como um todo carece de consistência interna (Dess \& Davis, 1984). 


\section{Figura 3 - Estratégias Genéricas de Porter}

\begin{tabular}{|c|c|c|c|}
\hline \multirow{4}{*}{$\begin{array}{c}\text { ESCOPO } \\
\text { COMPETITIVO }\end{array}$} & \multirow[b]{3}{*}{ Alvo Amplo } & \multicolumn{2}{|c|}{ VANTAGEM COMPETITIVA } \\
\hline & & Custo Mais Baixo & Diferenciação \\
\hline & & 1. Liderança no Custo Total & 2. Diferenciação \\
\hline & Alvo Estreito & 3A. Enfoque em Custo & $\begin{array}{l}\text { 3B. Enfoque em } \\
\text { Diferenciação }\end{array}$ \\
\hline
\end{tabular}

Liderança no Custo Total: O ponto central da estratégia de liderança no custo total é a empresa fazer com que seu custo total seja menor do que o de seus concorrentes. $\mathrm{O}$ custo mais baixo funciona como um mecanismo de defesa da empresa contra a rivalidade de seus concorrentes, especialmente no tocante à guerra de preços. Quando pressionada por fornecedores poderosos, a empresa de custo mais baixo terá mais fôlego para continuar na indústria do que seus concorrentes que também estão sujeitos à pressão desses fornecedores. Raciocínio similar vale para a análise da empresa vis-à-vis as demais forças competitivas (ameaça de novos entrantes, ameaça de produtos substitutos e poder de negociação dos compradores).

Diferenciação: A estratégia de diferenciação pressupõe que a empresa ofereça, no âmbito de toda a indústria, um produto que seja considerado único pelos clientes, ou seja, cujas características o distingam daqueles oferecidos pela concorrência. Hunt \& Morgan (1995) comentam que a heterogeneidade dos gostos e necessidades dos clientes torna difícil falar-se em um mercado que atinja toda a indústria, quando, na realidade, existem segmentos de mercado. Contudo, o conceito de um produto que atenda a toda a indústria assenta-se no fato de que podem existir características gerais que são valorizadas pela maioria dos segmentos de mercado dentro da indústria.

A diferenciação oferece à empresa uma defesa contra as forças do ambiente, embora de uma forma diferente daquela permitida pela liderança em custo. A lealdade dos consumidores e a diminuição da sensibilidade ao preço (i.e., clientes dispostos a pagar mais para terem um produto que eles consideram que melhor atende às suas necessidades) isolam, em maior ou menor grau, a empresa da rivalidade de seus concorrentes. Similarmente, o poder de barganha dos compradores também diminui, uma vez que (por definição de produto diferenciado) eles não encontrarão no mercado outro produto com as mesmas características. Argumentação similar pode ser aplicada na análise da vulnerabilidade da empresa em relação aos entrantes potenciais e aos produtos substitutos.

Considerando-se que a diferenciação pode permitir à empresa cobrar um preço prêmio e desde que este preço prêmio cubra os eventuais custos adicionais em que a empresa incorre para diferenciar seu produto (ex: $\mathrm{P} \& \mathrm{D}$, qualidade dos insumos, melhor nível de serviço, propaganda, etc.), a empresa possuirá uma margem maior que a de seus concorrentes, o que a tornará menos vulnerável do que estes em relação às pressões do ambiente.

Enfoque: A estratégia de enfoque se baseia no fato de que a empresa será capaz de atender melhor ao seu alvo estratégico do que aqueles concorrentes que buscam atender a toda a indústria (ou a um grande número de segmentos da indústria). $\mathrm{O}$ alvo, ou escopo, estratégico deve ser suficientemente estreito de forma a permitir que a empresa o atenda mais eficientemente ou mais eficazmente e pode ser definido sob diversas dimensões: tipos de clientes, linha de produtos, variedade do canal de distribuição, área geográfica, etc. $\mathrm{O}$ alvo estreito pode ser atendido através de uma posição de custo mais baixo ou de 
uma posição de diferenciação, mesmo que a empresa não seja capaz de manter uma destas posições em relação à indústria como um todo.

\section{Estratégias Genéricas de Mintzberg (1988)}

Mintzberg (1988) entende que a maioria das tipologias estratégicas explicitadas são falhas, seja por focarem de forma muito estreita em alguns tipos especiais de estratégias, seja por proporem agregações arbitrárias. Mintzberg (1988) propôs uma nova tipologia de estratégias genéricas, derivadas a partir do conceito de diferenciação e com um nível de detalhamento maior que as estratégias de Porter (Figura 4).

Figura 4 - Estratégias Genéricas de Mintzberg

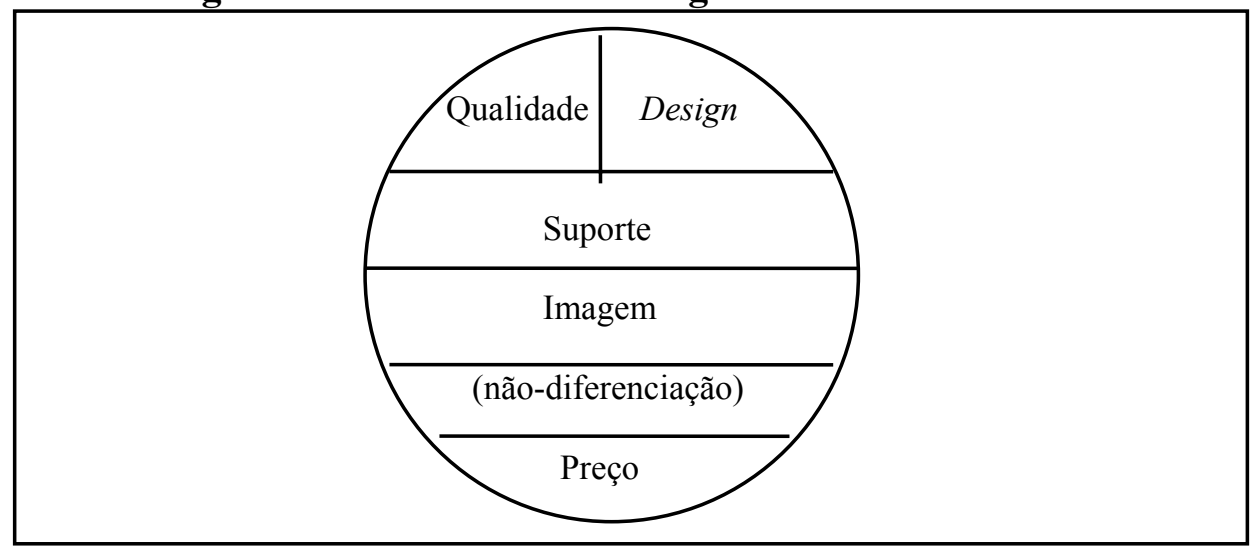

Diferenciação por qualidade: Esta estratégia se caracteriza por oferecer um produto que, embora não fundamentalmente diferente, é melhor que o dos concorrentes: (a) maior confiabilidade, (b) maior durabilidade ou (c) desempenho superior. Ao contrário da diferenciação por imagem, que Mintzberg entende como derivada de investimentos em propaganda e promoção, a diferenciação por qualidade advém dos atributos do próprio produto em si.

Diferenciação por design (projeto): Uma forma de diferenciar um produto é oferecê-lo ao mercado com características distintas dos produtos concorrentes. Trata-se, na verdade, de oferecer um produto diferente, em substituição aos da concorrência. A diferença básica desta estratégia para aquela de diferenciação por qualidade é que a diferenciação por design busca efetivamente oferecer algo diferente e não simplesmente ou necessariamente melhor.

Diferenciação por suporte: Uma forma de diferenciar o produto, sem necessariamente alterar seus atributos intrínsecos é oferecer algo mais junto com o produto — em geral, a ampliação do nível de serviços agregados (prazo de entrega menor, financiamento à venda, assistência técnica) ou a oferta de produtos complementares.

Diferenciação por imagem: Uma vez que um dos atributos de um produto é a forma como os consumidores o percebem em comparação com os produtos concorrentes ou substitutos, uma empresa pode diferenciar seu produto ao desenvolver uma imagem que o torne distinto dos demais. Esta imagem pode ser criada através de propaganda, como também através de técnicas de promoção, apresentação e embalagem do produto, ou inclusão de detalhes que, embora não melhorando o desempenho do produto, o tornam mais atrativo para alguns clientes. 
Diferenciação por preço: Uma forma de diferenciar um produto da oferta dos outros concorrentes pode ser, simplesmente, cobrar um preço mais baixo. Se os demais atributos do produto forem iguais, ou não muito diferentes, dos de seus concorrentes, os consumidores tenderão a preferir aquele que exibir um preço mais baixo. Mintzberg insiste em afirmar que diferenciação por preço não é o mesmo que minimização de custo (conforme Porter, 1980), posto que, em sua opinião, esta última somente se caracterizaria como uma vantagem competitiva caso se traduzisse num menor preço para o mercado (ou seja, caso fosse visível para o consumidor).

Não-diferenciação: Trata-se de uma estratégia muito observada na prática, a qual se baseia no fato de que é possível copiar as ações de outras empresas, desde que o mercado ofereça espaço para produtos concorrentes e a empresa se especialize em acompanhar e imitar os lançamentos dos concorrentes e apoiar seus próprios lançamentos com ações inovadoras e eficientes de marketing. A estratégia de não-diferenciação assemelha-se ao conceito de meio-termo desenvolvido por Porter (1980). Duas diferenças, no entanto, merecem destaque:

a) Mintzberg considera que a estratégia de não-diferenciação pode ser desenvolvida explicitamente, enquanto Porter considera o meio-termo como um tipo residual, resultante da implementação inadequada ou ineficiente de uma das estratégias genéricas puras.

b) Ao contrário do que Porter supõe para o meio-termo, Mintzberg não condena a estratégia de não-diferenciação a um desempenho inferior ao das demais estratégias.

\section{METODOLOGIA}

A pesquisa foi conduzida como um estudo de casos, tendo sido preliminarmente investigadas 62 empresas de petróleo, distribuídas por todos os continentes. Destas, 10 foram selecionadas para comporem a pesquisa detalhada, das quais apenas seis retornaram respostas a um número suficiente de perguntas de forma a atender plenamente aos requisitos de classificação. A justificativa por se ter optado por um estudo de casos pode ser encontrada em Bonoma (1985), o qual entende que os diferentes tipos de pesquisa se situam ao longo de um continuum (Figura 5).

A busca por relações de causa-efeito se torna importante e eficaz apenas quando o corpo teórico já se encontra suficientemente desenvolvido (Bonoma, 1985, p.202).

\section{Figura 5 - Objetivos de Pesquisas}

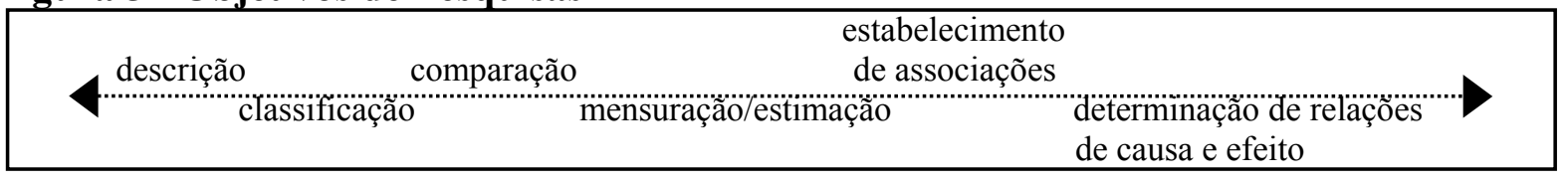

O fenômeno de desregulamentação de indústrias e eventual privatização de empresas é complexo e multifacetado. Neste presente artigo não foi apresentado nem desenvolvido um modelo teórico que fundamente o estabelecimento de relações causais. Ao contrário, com base em um modelo teórico da relação ambiente-estratégia-desempenho (Porter, 1980, 1985), este estudo visa apenas a comparar a aplicabilidade de dois modelos de estratégias genéricas (Porter e Mintzberg), ao mesmo tempo em que pretende contextualizar as estratégias das empresas de petróleo que foram privatizadas de acordo com o modelo de análise estrutural de indústrias de Porter (1980), o qual também pretende ser genérico (mas a 
ESTRATÉGIA - IMPACTOS DA PRIVATIZAÇÃO SOBRE AS ESTRATÉGIAS COMPETITIVAS DE EMPRESAS

DE PETRÓLEO: UM ESTUDO DE CASOS

JORGE MANOEL TEIXEIRA CARNEIRO - JORGE FERREIRA DA SILVA - MARIA ALICE D. FERREIRA CAVALCANTI

validação deste modelo de análise de indústrias não fez parte da presente pesquisa). O intuito é, portanto, apresentar as modificações do ambiente competitivo segundo o modelo da estrutura da indústria (Porter, 1980) e verificar se cada uma daquelas duas tipologias estratégicas (supostamente genéricas) seria adequada à classificação das estratégias de empresas (neste caso, empresas de petróleo) em contexto de significativa transformação (neste caso, desregulamentação) de seus ambientes competitivos.

Embora o modelo teórico escolhido pareça, a priori, apropriado, é possível que se verifique, eventualmente, que ele não se presta adequadamente para descrever e explicar a dinâmica de modificação do ambiente competitivo e a adaptação das empresas em face da desregulamentação. Mas isto faz parte do desenvolvimento da teoria e da investigação da validade externa, i.e., da generalidade da taxinomia de estratégias genéricas. O presente estudo atenderá à etapa de descrição e se juntará a outros conceitualmente semelhantes (vide, por exemplo, Cavalcanti, 1997 e Rodrigues, 1995) de forma a construir um corpo teórico adequado para a posterior implementação das etapas de classificação até relação causa-efeito (conforme Bonoma, 1985).

O estudo de casos se revela uma ferramenta útil, uma vez que o objetivo desta pesquisa não é quantificar — o que exigiria amostras grandes —, mas sim descrever um fenômeno e contribuir para a futura extensão ou adaptação do modelo teórico utilizado. O presente estudo deverá servir, portanto, como componente de um conhecimento cumulativo.

Com relação a (i) coleta de dados retrospectivos, (ii) controle sobre a veracidade das respostas e (iii) método de interpretação das respostas e identificação da estratégia, se fazem necessárias considerações para entender algumas limitações do presente estudo.

No que tange a dados retrospectivos, Golden (1992) identificou considerável inconsistência entre as avaliações sobre as estratégias de empresas fornecidas num determinado ano e aquelas fornecidas dois anos depois, relativas ao mesmo período anteriormente pesquisado. No caso da presente pesquisa, também é possível que os respondentes não possuam uma visão muito clara da estratégia e do ambiente competitivo passados, especialmente naqueles casos em que o respondente não fosse empregado da empresa antes da desregulamentação.

Contudo, ao contrário da pesquisa de Golden, onde os respondentes receberam uma descrição de quatro arquétipos estratégicos e foi-lhes solicitado que associassem sua empresa com um desses arquétipos, na presente pesquisa os respondentes foram indagados sobre questões mais específicas, como métodos competitivos adotados. Embora nenhum estudo (ao menos que seja do conhecimento dos autores deste trabalho) tenha avaliado se esta técnica é menos sujeita a erros retrospectivos do que aquela empregada por Golden, é provável que a utilização de perguntas mais específicas e mais próximas ao dia-a-dia dos respondentes tenda a diminuir os erros na identificação das estratégias passadas.

Quanto ao controle sobre as respostas aos questionários, Huber \& Power (1985) citam quatro razões primárias para explicar porque respondentes produziriam respostas incorretas ou enviesadas: (a) eles estão motivados a fazê-lo, (b) suas limitações perceptuais e cognitivas resultam em erros inadvertidos, (c) eles não possuem informações cruciais sobre os eventos de interesse ou (d) eles foram questionados através de procedimentos ou instrumentos não apropriados. Cada um destes pontos mereceu a devida consideração na pesquisa. No entanto, especificamente com relação à primeira razão, existe a possibilidade de que os respondentes estejam buscando validar suas próprias decisões tomadas após a privatização e legitimando, a posteriori, uma racionalidade estratégica que é compatível com o modelo 
de estratégia que vem sendo amplamente difundido e aceito na indústria há aproximadamente duas décadas (os autores são gratos a um revisor anônimo por este comentário).

Com relação à identificação da estratégia de cada empresa, vale citar que o conceito de estratégia envolve considerável complexidade de mensuração e operacionalização. Conforme Snow \& Hambrick (1980), a identificação e mensuração das estratégias pode se apoiar em quatro técnicas básicas: (1) inferência do investigador, (2) auto-classificação, (3) avaliação externa e (4) uso de indicadores objetivos. A estas técnicas pode ainda ser acrescentada uma outra, citada por Conant et al. (1990) e também muito utilizada na literatura: (5) auto-classificação com regras de decisão especificadas pelo investigador. Nesta pesquisa foi utilizada a técnica de auto-classificação com regras de decisão especificadas pelo investigador. As estratégias foram, assim, inferidas a partir da ênfase ou importância relativas dadas a cada uma das dimensões componentes e as regras de classificação indicavam basicamente como cada dimensão componente (no questionário chamada de competitive method) se relaciona com cada uma das estratégias de liderança em custo, diferenciação e enfoque (tipologia de Porter) ou com cada uma das estratégias de diferenciação por qualidade, por design, por suporte, por imagem e por preço (tipologia de Mintzberg).

\section{COLETA E TRATAMENTO DOS DADOS}

As informações sobre a ênfase (relativa aos concorrentes) dedicada a cada um dos métodos competitivos, assim como a avaliação sobre a intensidade das cinco forças da estrutura da indústria, foram obtidas a partir das respostas a um questionário respondido por Gerentes da hierarquia superior das empresas: Vice-Presidentes, Diretores e Gerentes Funcionais (os Quadros 1 e 2 apresentam exemplos de perguntas contidas no questionário).

As respostas das empresas foram complementadas por informações contidas em seus Relatórios Anuais de Atividades e por material adicional enviado pelas empresas: Lei da Privatização, prospectos da privatização, comunicações ao mercado, etc.

Além disso, foram ainda acrescidas informações levantadas em relatórios de algumas empresas de consultoria, bem como em revistas especializadas na área de petróleo e publicações da área econômica.

\section{Quadro 1 - Exemplo de pergunta sobre métodos competitivos}

How much relative emphasis does your company place on each of the following competitive methods as part of your company's overall strategy?

1 - New product development (research \& development, rate of innovation and launching, participation of new products in total sales, number of patents)

Since 19XX (that is, after privatisation):

\begin{tabular}{|c|c|c|c|c|}
\hline $\begin{array}{c}\text { much less } \\
\text { than } \\
\text { competitors' } \\
\text { average }\end{array}$ & $\begin{array}{c}\text { a little less } \\
\text { than } \\
\text { competitors } \\
\text { average }\end{array}$ & $\begin{array}{c}\text { about the } \\
\text { same as } \\
\text { competitors } \\
\text { average }\end{array}$ & $\begin{array}{l}\text { a little more } \\
\text { than } \\
\text { competitors' } \\
\text { average }\end{array}$ & $\begin{array}{l}\text { much more } \\
\text { than } \\
\text { competitors' } \\
\text { average }\end{array}$ \\
\hline
\end{tabular}




\section{Quadro 2 - Exemplo de pergunta sobre forças da estrutura da indústria}

\section{Bargaining Power of Buyers}

21 - Level of effective power that buyers exert in order to get price reductions, extension of payment schedules or augmentation in services received - all of which help increase buyers' own profitability.

Buyers' power tends to be greatest when:

. buyers can easily get alternative substitute products

. buyers are less in number and bigger in size than firms in the oil and gas industry

Since 19XX (that is, after privatisation):

$\square$ Buyers exert much more bargaining power than oil and gas companies

$\square$ Buyers exert more bargaining power than oil and gas companies

$\square$ Bargaining power is well balanced between buyers and oil and gas companies

Buyers exert less bargaining power than oil and gas companies

$\square$ Buyers exert much less bargaining power than oil and gas companies

Seis empresas responderam integralmente à pesquisa, enviando não apenas o questionário, mas também o material complementar.

Duas empresas, Europa \#4 e Europa \#7, responderam apenas parcialmente ao questionário. Contudo, ambas as empresas enviaram o material complementar solicitado, o que tornou possível uma análise, ainda que mais simplificada, de suas estratégias. Suas respostas estão incluídas nas tabelas 2 e 3, mas a análise de suas estratégias, por ser consideravelmente simplificada, não está publicada neste texto nem apresentada na tabela 4 .

Por fim, duas empresas, Europa \#3 e Europa \#6, não responderam ao questionário. A Europa \#3 alegou que a desregulamentação do setor e a privatização da empresa não haviam implicado em qualquer alteração em suas estratégias. A Europa \#6 alegou que atua em vários segmentos de negócio, cada um dos quais com uma estratégia não necessariamente idêntica às dos demais. Por esta razão, a empresa teria encontrado dificuldades para responder a um questionário, que indagava sobre "a" estratégia da empresa.

Conforme já mencionado, a técnica de coleta de dados adotada foi a de auto-classificação com regras de decisão especificadas pelo investigador, tendo sido utilizados 18 métodos competitivos (vide Tabela 3). A definição das regras de classificação foi realizada de acordo com orientação básica de Dess \& Davis (1984) e de Kotha \& Vadlamani (1995), e foi conduzida por um painel de três especialistas. A utilização de painéis de especialistas é sugerida por Harrigan (1983) como forma de se refinarem e corroborarem inferências obtidas a partir de pesquisa de campo. Combinam-se, assim, a capacidade descritiva da pesquisa de campo com as recomendações normativas do painel de especialistas.

As Tabelas 2 e 3 relacionam as respostas ao questionário. Conforme acordado com as empresas, o nome de cada uma delas está mantido em sigilo. Os itens em branco se referem às perguntas não respondidas do questionário. 


\section{ANÁLISE DOS DADOS}

\section{Estrutura da Indústria}

Os dados colhidos permitem concluir que a desregulamentação da indústria do petróleo nesses países tornou o ambiente mais hostil (Tabela 2), o que tenderia a diminuir o retorno médio das empresas no setor. Via de regra, diminuíram as barreiras à entrada de novos concorrentes (devido à flexibilização da lei e à permissão de importação) e aumentou o nível de rivalidade, (devido à flexibilização das regras e ao aumento do número de concorrentes), assim como aumentou o poder de negociação dos fornecedores e dos compradores (como há mais empresas concorrendo, cada uma, em média, detém um menor volume de mercado, o que lhes retira poder de barganha com relação aos fornecedores e aos compradores).

A ameaça de produtos substitutos continuou inalterada (na verdade, pode ser observado um aumento da participação do gás natural, em substituição ao petróleo, na matriz energética mundial; contudo, como as empresas de petróleo também atuam, via de regra, no segmento de gás natural, a ameaça de fontes alternativas ao binômio petróleo-gás continua praticamente inalterada).

\section{Tabela 2 - Caracterização das Forças do Ambiente Competitivo Antes e Após a Privatização}

\begin{tabular}{|c|c|c|c|c|c|c|c|c|c|c|c|c|c|c|c|c|c|c|c|c|c|c|c|c|c|c|}
\hline \multirow{10}{*}{ 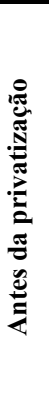 } & & \multicolumn{5}{|c|}{$\begin{array}{l}\text { ameaça de novos } \\
\text { entrantes }\end{array}$} & \multicolumn{5}{|c|}{$\begin{array}{l}\text { Poder de barganha } \\
\text { relativo dos } \\
\text { fornecedores }\end{array}$} & \multicolumn{5}{|c|}{$\begin{array}{c}\text { Poder de barganha } \\
\text { relativo dos } \\
\text { compradores } \\
\end{array}$} & \multicolumn{5}{|c|}{$\begin{array}{l}\text { intensidade da } \\
\text { rivalidade }\end{array}$} & \multicolumn{5}{|c|}{$\begin{array}{l}\text { ameaça de produtos e } \\
\text { serviços substitutos }\end{array}$} \\
\hline & & 1 & 2 & 3 & 4 & 5 & 1 & 2 & 3 & 4 & 5 & 1 & 2 & 3 & 4 & 5 & 1 & 2 & 3 & 4 & 5 & 1 & 2 & 3 & 4 & 5 \\
\hline & África \#1 & $\mathbf{X}$ & & & & & $\bar{X}$ & & & & & & $\mathrm{X}$ & & & & & $\mathbf{X}$ & & & & & $\mathbf{X}$ & & & \\
\hline & Américas \#1 & $\mathbf{X}$ & & & & & & & & & $\mathbf{X}$ & $\mathbf{X}$ & & & & & & & $\mathbf{X}$ & & & & $\mathbf{X}$ & & & \\
\hline & Américas \#2 & & $\mathbf{X}$ & & & & & & $\mathbf{X}$ & & & & & $\mathbf{X}$ & & & & & & & $\mathbf{X}$ & $\mathbf{X}$ & & & & \\
\hline & Europa \#1 & $\mathbf{X}$ & & & & & $\mathbf{X}$ & & & & & & $\mathbf{X}$ & & & & & & & $\mathbf{X}$ & & $\mathbf{X}$ & & & & \\
\hline & Europa \#2 & & $\mathbf{X}$ & & & & & & & $\mathbf{X}$ & & & $\mathbf{X}$ & & & & & $\mathbf{X}$ & & & & & $\mathbf{X}$ & & & \\
\hline & Europa \#4 & & & & & & & & & & & & & & & & & & & & & & & & & \\
\hline & Europa \#5 & & & $\mathbf{X}$ & & & & $\mathbf{X}$ & & & & & $\mathbf{X}$ & & & & & & & $\mathbf{X}$ & & $\mathbf{X}$ & & & & \\
\hline & Europa \#7 & $\mathbf{X}$ & & & & & & & $\mathbf{X}$ & & & & & $\mathbf{X}$ & & & & & $\mathbf{X}$ & & & & $\mathbf{X}$ & & & \\
\hline
\end{tabular}

\begin{tabular}{|c|c|c|c|c|c|c|c|c|c|c|c|c|c|c|c|c|c|c|c|c|c|c|c|c|c|c|}
\hline \multirow{10}{*}{ 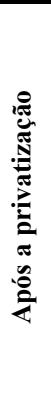 } & & \multicolumn{5}{|c|}{$\begin{array}{l}\text { ameaça de novos } \\
\text { entrantes }\end{array}$} & \multicolumn{5}{|c|}{$\begin{array}{c}\text { Poder de barganha } \\
\text { relativo dos } \\
\text { fornecedores }\end{array}$} & \multicolumn{5}{|c|}{$\begin{array}{c}\text { poder de barganha } \\
\text { relativo dos } \\
\text { compradores }\end{array}$} & \multicolumn{5}{|c|}{$\begin{array}{l}\text { intensidade da } \\
\text { rivalidade }\end{array}$} & \multicolumn{5}{|c|}{$\begin{array}{l}\text { ameaça de produtos e } \\
\text { serviços substitutos }\end{array}$} \\
\hline & & 1 & 2 & 3 & 4 & 5 & 1 & 2 & 3 & 4 & 5 & 1 & 2 & 3 & 4 & 5 & 1 & 2 & 3 & 4 & 5 & 1 & 2 & 3 & 4 & 5 \\
\hline & África \#1 & & $\mathbf{X}$ & & & & & $\mathbf{X}$ & & & & & & $\mathbf{X}$ & & & & & $\mathbf{X}$ & & & & $\mathbf{X}$ & & & \\
\hline & Américas \#1 & & & & & $\mathbf{X}$ & & & $\mathbf{X}$ & & & & & & $\mathbf{X}$ & & & & & & $\mathbf{X}$ & & $\mathbf{X}$ & & & \\
\hline & Américas \#2 & & & $\mathbf{X}$ & & & & & $\mathbf{X}$ & & & & & $\mathbf{X}$ & & & & & & & $\mathbf{X}$ & $\mathbf{X}$ & & & & \\
\hline & Europa \#1 & & $\mathbf{X}$ & & & & & $\mathbf{X}$ & & & & & & & $\mathbf{X}$ & & & & & $\mathbf{X}$ & & $\mathrm{X}$ & & & & \\
\hline & Europa \#2 & & & $\mathbf{X}$ & & & & & $\mathbf{X}$ & & & & & $\mathbf{X}$ & & & & & & & $\mathbf{X}$ & & $\mathbf{X}$ & & & \\
\hline & Europa \#4 & & & & & & & & & & & & & & & & & & & & & & & & & \\
\hline & Europa \#5 & & & & $\bar{X}$ & & & $\mathbf{X}$ & & & & & & & $\bar{X}$ & & & & & & $\bar{X}$ & $\mathbf{X}$ & & & & \\
\hline & Europa \#7 & & & $\mathbf{X}$ & & & & & $\mathbf{X}$ & & & & & & $\mathbf{X}$ & & & & & $\mathbf{X}$ & & & $\mathbf{X}$ & & & \\
\hline
\end{tabular}

Intensidade das Forças:
1 - muito baixa
2 - baixa
3 - nem alta nem baixa (equilibrada)
4 - alta
5 - muito alta 
Antes da privatização, a maioria das empresas não apresentava uma definição clara de sua estratégia, ao menos sob a ótica da visão competitiva que norteia os modelos de Porter e Mintzberg. Enquanto alguns métodos competitivos não eram enfatizados o suficiente, outros métodos apareciam isolados e careciam do reforço de métodos complementares (vide Tabela 3 ).

No entanto, após a privatização, a maioria das empresas passou a buscar uma maior clareza e direcionamento estratégico, através da ênfase mais intensa em determinados métodos competitivos, voltados principalmente para a implementação de uma estratégia de diferenciação, apoiada por paridade de custos (vide Tabela 3). Esta postura afasta a empresa da posição de meio-termo e a aproxima de um dos tipos estratégicos que Porter e Mintzberg consideram vencedores.

Em resposta às mudanças nas regras de concorrência, as antigas empresas estatais procuraram se reposicionar no mercado e melhorar seu desempenho através da adoção de estratégias de diferenciação, especialmente no tocante ao reforço da imagem da marca, realizando investimentos em publicidade e aprimorando a identidade visual dos postos de serviço. Vale a pena notar-se que, mesmo naqueles casos em que não houve aumento expressivo nos gastos com propaganda, o perfil destes gastos mudou consideravelmente: as empresas reduziram seus gastos com propaganda institucional em nome do Governo e passaram a enfatizar seus produtos e serviços.

A empresa África \#1 procurou se diferenciar principalmente através da melhoria da qualidade dos produtos e do reforço da imagem, em especial pelo controle sobre os canais de distribuição.

\section{Tabela 3 - Ênfase Relativa em cada um dos Métodos Competitivos Antes e Após a Privatização (1" parte)}

\begin{tabular}{|c|c|c|c|c|c|c|c|c|c|c|c|c|c|c|c|c|c|c|c|c|c|c|c|c|c|c|c|c|c|c|c|}
\hline \multirow{10}{*}{ 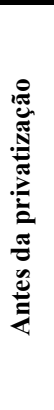 } & & \multicolumn{5}{|c|}{$\begin{array}{l}1-\text { desenvolvi- } \\
\text { mento de novos } \\
\text { produtos }\end{array}$} & \multicolumn{5}{|c|}{$\begin{array}{c}2 \text { - nível de } \\
\text { características } \\
\text { diferenciadoras }\end{array}$} & \multicolumn{5}{|c|}{$\begin{array}{l}3 \text { - nível de } \\
\text { serviço }\end{array}$} & \multicolumn{5}{|c|}{$\begin{array}{l}4 \text { - financiamento } \\
\text { às vendas }\end{array}$} & \multicolumn{5}{|c|}{$\begin{array}{l}5 \text { - qualidade dos } \\
\text { produtos }\end{array}$} & \multicolumn{5}{|c|}{$\begin{array}{l}6 \text { - nível de } \\
\text { estoque }\end{array}$} \\
\hline & & 1 & 2 & 3 & 4 & 5 & 1 & 2 & 3 & 4 & 5 & 1 & 2 & 3 & 4 & 5 & 1 & 2 & 3 & 4 & 5 & 1 & 2 & 3 & 4 & 5 & 1 & 2 & 3 & 4 & 5 \\
\hline & África \#1 & & & & & $\mathbf{X}$ & & & $\mathbf{X}$ & & & & & $\mathbf{X}$ & & & & $\mathbf{X}$ & & & & & & $\mathbf{X}$ & & & & & & $\mathbf{X}$ & \\
\hline & Américas \#1 & & $\mathbf{X}$ & & & & $\mathbf{X}$ & & & & & $\mathbf{X}$ & & & & & & & $\mathbf{X}$ & & & & & $\mathbf{X}$ & & & & & & & $\mathbf{X}$ \\
\hline & Américas \#2 & & & $\mathbf{X}$ & & & & & $\mathbf{X}$ & & & & & $\mathbf{X}$ & & & & & $\mathbf{X}$ & & & & & $\mathbf{X}$ & & & & & & $\mathbf{X}$ & \\
\hline & Europa \#1 & & & $\mathbf{X}$ & & & & & & $\mathbf{X}$ & & & & $\mathbf{X}$ & & & & & & $\mathbf{X}$ & & & & $\mathbf{X}$ & & & & & $\mathbf{X}$ & & \\
\hline & Europa \#2 & & & $\mathbf{X}$ & & & & & $\mathbf{X}$ & & & & & & $\mathbf{X}$ & & & & & $\mathbf{X}$ & & & & $\mathbf{X}$ & & & & & $\mathbf{X}$ & & \\
\hline & Europa \#4 & & & & & & & & & & & & & & & & & & & & & & & & & & & & & & \\
\hline & Europa \#5 & $\mathbf{X}$ & & & & & & & $\mathbf{X}$ & & & & & & $\mathbf{X}$ & & & & & $\mathbf{X}$ & & & & & & & & & & & $\mathbf{X}$ \\
\hline & Europa \#7 & & & & & $\mathbf{X}$ & & & & & & & & & & $\mathbf{X}$ & & & & & & & & & $\mathbf{X}$ & & & & & & $\mathbf{X}$ \\
\hline
\end{tabular}

\begin{tabular}{|c|c|c|c|c|c|c|c|c|c|c|c|c|c|c|c|c|c|c|c|c|c|c|c|c|c|c|c|c|c|c|c|}
\hline \multirow{10}{*}{ 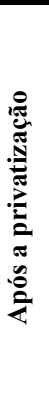 } & & \multicolumn{5}{|c|}{$\begin{array}{l}1 \text { - desenvolvi- } \\
\text { mento de novos } \\
\text { produtos }\end{array}$} & \multicolumn{5}{|c|}{$\begin{array}{c}2 \text { - nível de } \\
\text { características } \\
\text { diferenciadoras }\end{array}$} & \multicolumn{5}{|c|}{$\begin{array}{l}3 \text { - nível de } \\
\text { serviço }\end{array}$} & \multicolumn{5}{|c|}{$\begin{array}{l}4 \text { - financiamento } \\
\text { às vendas }\end{array}$} & \multicolumn{5}{|c|}{$\begin{array}{l}5 \text { - qualidade dos } \\
\text { produtos }\end{array}$} & \multicolumn{5}{|c|}{$\begin{array}{l}6 \text { - nível de } \\
\text { estoque }\end{array}$} \\
\hline & & \begin{tabular}{l|l}
1 & \\
\end{tabular} & 2 & 3 & 4 & 5 & \begin{tabular}{l|l}
1 & \\
\end{tabular} & 2 & 3 & 4 & 5 & 1 & 2 & 3 & 4 & 5 & 1 & 2 & 3 & 4 & 5 & 1 & 2 & 3 & 4 & 5 & 1 & 2 & 3 & 4 & 5 \\
\hline & África \#1 & & & & & $X$ & & & & $\mathbf{X}$ & & & & $\mathbf{X}$ & & & & & $\mathbf{X}$ & & & & & & $\mathbf{X}$ & & & & $\mathbf{X}$ & & \\
\hline & Américas \#1 & & & $\mathbf{X}$ & & & & & & $\mathbf{X}$ & & & & & $\mathbf{X}$ & & & & $\mathbf{X}$ & & & & & & $\mathbf{X}$ & & & & $\bar{X}$ & & \\
\hline & Américas \#2 & & & & & $\mathbf{X}$ & & & & $\mathbf{X}$ & & & & & $\mathbf{X}$ & & & & $\mathbf{X}$ & & & & & & $\mathbf{X}$ & & & & $\mathbf{X}$ & & \\
\hline & Europa \#1 & & & $\mathbf{X}$ & & & & & $\mathbf{X}$ & & & & & & $\mathbf{X}$ & & & & & $\mathbf{X}$ & & & & $\mathbf{X}$ & & & & & $\mathbf{X}$ & & \\
\hline & Europa \#2 & & & & $\mathbf{X}$ & & & & & $\mathbf{X}$ & & & & & & $\mathbf{X}$ & & & & & $\mathbf{X}$ & & & & $\mathbf{X}$ & & & & $\mathbf{X}$ & & \\
\hline & Europa \#4 & & & & & & & & & & & & & & & & & & & & & & & & & & & & & & \\
\hline & Europa \#5 & & & & $\mathbf{X}$ & & & & & $\mathbf{X}$ & & & & & $\mathbf{X}$ & & & & $\mathbf{X}$ & & & & & & & & & & $\mathbf{X}$ & & \\
\hline & Europa \#7 & & & & $\mathrm{X}$ & & & & & & & & & & $X$ & & & & & & & & & & $\mathbf{X}$ & & & & & $\bar{X}$ & \\
\hline
\end{tabular}




\section{Tabela 3 - Ênfase Relativa em cada um dos Métodos Competitivos Antes e Após a Privatização $\left(2^{\mathrm{a}}\right.$ parte)}

\begin{tabular}{|c|c|c|c|c|c|c|c|c|c|c|c|c|c|c|c|c|c|c|c|c|c|c|c|c|c|c|c|c|c|c|c|}
\hline \multirow{10}{*}{ 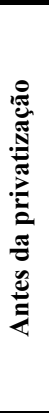 } & & \multicolumn{5}{|c|}{7 - Preço } & \multicolumn{5}{|c|}{$\begin{array}{l}8 \text { - amplitude da } \\
\text { linha de produtos }\end{array}$} & \multicolumn{5}{|c|}{$\begin{array}{c}9 \text { - identificação e } \\
\text { reputação de } \\
\text { marca }\end{array}$} & \multicolumn{5}{|c|}{$\begin{array}{l}10 \text { - controle sobre } \\
\text { os canais de } \\
\text { distribuição }\end{array}$} & \multicolumn{5}{|c|}{$\begin{array}{c}11- \\
\text { disponibilidade de } \\
\text { matéria-prima }\end{array}$} & \multicolumn{5}{|c|}{$\begin{array}{c}12 \text { - mercados } \\
\text { especiais (nichos) }\end{array}$} \\
\hline & & 1 & 2 & 3 & 4 & 5 & 1 & 2 & 3 & 4 & 5 & 1 & 2 & 3 & 4 & 5 & 1 & 2 & \begin{tabular}{|l|}
3 \\
\end{tabular} & 4 & 5 & 1 & 2 & \begin{tabular}{|l|}
3 \\
\end{tabular} & \begin{tabular}{l|l}
4 \\
\end{tabular} & 5 & 1 & 2 & 3 & 4 & 5 \\
\hline & África \#1 & & & $\mathbf{X}$ & & & & & & $\mathbf{X}$ & & & & & & $\mathbf{X}$ & & & $\mathbf{X}$ & & & & & & $\mathbf{X}$ & & & $\mathbf{X}$ & & & \\
\hline & Américas \#1 & & & $\mathbf{X}$ & & & & & & & $\mathbf{X}$ & $\mathbf{X}$ & & & & $\mathbf{x}$ & $\mathbf{X}$ & & & & & & & $\mathbf{X}$ & & & & $\mathbf{X}$ & & & \\
\hline & Américas \#2 & & & $\mathbf{X}$ & & & & & $\mathbf{X}$ & & & & & & $\mathbf{X}$ & & & & $\mathbf{X}$ & & & & & $\mathbf{X}$ & & & & & $\mathbf{X}$ & & \\
\hline & Europa \#1 & & & $\mathbf{X}$ & & & & & & $\mathbf{X}$ & & & & & $\mathbf{X}$ & & & $\mathbf{X}$ & & & & $\mathbf{X}$ & & & & & & & & $\mathbf{X}$ & \\
\hline & Europa \#2 & & & & $\mathbf{X}$ & & & & & $\mathbf{X}$ & & & & & $\mathbf{X}$ & & & & & $\mathbf{X}$ & & & & $\mathbf{X}$ & & & & $\mathbf{X}$ & & & \\
\hline & Europa \#4 & & & & & & & & & & & & & & & & & & & & & & & & & & & & & & \\
\hline & Europa \#5 & & & $\mathbf{X}$ & & & & & $\mathbf{X}$ & & & & & & & $\mathbf{X}$ & & & & & $\mathbf{X}$ & & $\mathbf{X}$ & & & & & & & & \\
\hline & Europa \#7 & & & & & & & & & & & & & & & & & & & & & & & & & & & & & & \\
\hline \multirow{10}{*}{ 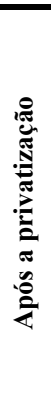 } & & \multicolumn{5}{|c|}{7 - Preço } & \multicolumn{5}{|c|}{$\begin{array}{l}8 \text { - amplitude da } \\
\text { linha de produtos }\end{array}$} & \multicolumn{5}{|c|}{$\begin{array}{l}9 \text { - identificação e } \\
\text { reputação de } \\
\text { marca }\end{array}$} & \multicolumn{5}{|c|}{$\begin{array}{l}10 \text { - controle sobre } \\
\text { os canais de } \\
\text { distribuição }\end{array}$} & \multicolumn{5}{|c|}{$\begin{array}{c}11- \\
\text { disponibilidade de } \\
\text { matéria-prima }\end{array}$} & \multicolumn{5}{|c|}{$\begin{array}{c}12 \text { - mercados } \\
\text { especiais (nichos) }\end{array}$} \\
\hline & & 1 & 2 & 3 & 4 & 5 & 1 & 2 & 3 & 4 & 5 & 1 & 2 & 3 & 4 & 5 & 1 & 2 & 3 & 4 & 5 & 1 & 2 & \begin{tabular}{|l|}
3 \\
\end{tabular} & 4 & 5 & 1 & 2 & 3 & 4 & 5 \\
\hline & África \#1 & & & $\mathbf{X}$ & & & & & & & $\mathbf{X}$ & & & & $\mathbf{X}$ & & & & & $\mathbf{X}$ & & & & $\mathbf{X}$ & & & & & $\mathbf{X}$ & & \\
\hline & Américas \#1 & & & $\mathbf{X}$ & & & & & & & $\mathbf{X}$ & & & & $\mathbf{X}$ & & & & $\mathbf{X}$ & & & & & & $\mathbf{X}$ & & & & $\mathbf{X}$ & & \\
\hline & Américas \#2 & & & $\mathbf{X}$ & & & & & & $\mathbf{X}$ & & & & & & $\mathbf{X}$ & & & $\mathbf{X}$ & & & & & & $\mathbf{X}$ & & & & $\mathbf{X}$ & & \\
\hline & Europa \#1 & & & $\mathbf{X}$ & & & & & $\mathbf{X}$ & & & & & & $\mathbf{X}$ & & & & $\mathbf{X}$ & & & & $\mathbf{X}$ & & & & & & $\mathbf{X}$ & & \\
\hline & Europa \#2 & & & & $\mathbf{X}$ & & & & & $\mathbf{X}$ & & & & & & $\mathbf{X}$ & & & & $\mathbf{X}$ & & & & & $\mathbf{X}$ & & & & & $\mathbf{X}$ & \\
\hline & Europa \#4 & & & & & & & & & & & & & & & & & & & & & & & & & & & & & & \\
\hline & Europa \#5 & & & & $\mathbf{X}$ & & & & $\mathbf{X}$ & & & & & & & $\mathbf{X}$ & & & & & $\mathbf{X}$ & & & $\mathbf{X}$ & & & & & & & \\
\hline & Europa \#7 & & $\mathbf{X}$ & & & & & & & & & & & & & $\mathbf{X}$ & & & & & & & & & & & & & & & \\
\hline
\end{tabular}

Ênfase em relação à média dos concorrentes:

$\mathbf{1}$ - muito menos $\mathbf{2}$ - menos $\mathbf{3}$ - aproximadamente a mesma $\mathbf{4}$ - mais $\mathbf{5}$ - muito mais

Tabela 3 - Ênfase Relativa em cada um dos Métodos Competitivos Antes e Após a Privatização (3 ${ }^{\mathrm{a}}$ parte)

\begin{tabular}{|c|c|c|c|c|c|c|c|c|c|c|c|c|c|c|c|c|c|c|c|c|c|c|c|c|c|c|c|c|c|c|c|}
\hline \multirow{10}{*}{ 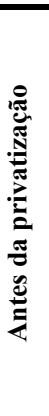 } & & \multicolumn{5}{|c|}{$\begin{array}{l}13 \text { - nível de } \\
\text { propaganda }\end{array}$} & \multicolumn{5}{|c|}{$\begin{array}{l}14 \text { - inovação em } \\
\text { processos de } \\
\text { produção }\end{array}$} & \multicolumn{5}{|c|}{$\begin{array}{c}15 \text { - busca } \\
\text { permanente por } \\
\text { redução de custos }\end{array}$} & \multicolumn{5}{|c|}{$\begin{array}{c}16 \text { - liderança } \\
\text { tecnológica }\end{array}$} & \multicolumn{5}{|c|}{$\begin{array}{l}17 \text { - mecanismos } \\
\text { de centralização e } \\
\text { coordenação }\end{array}$} & \multicolumn{5}{|c|}{$\begin{array}{c}18 \text { - relações com } \\
\text { o Governo }\end{array}$} \\
\hline & & 1 & 2 & 3 & 4 & 5 & 1 & 2 & 3 & 4 & 5 & \begin{tabular}{l|l}
1 & \\
\end{tabular} & 2 & 3 & 4 & 5 & 1 & 2 & 3 & 4 & 5 & 1 & 2 & \begin{tabular}{l|l}
3 & \\
\end{tabular} & 4 & 5 & 1 & 2 & 3 & 4 & 5 \\
\hline & África \#1 & & & $\mathbf{X}$ & & & & & & & $\mathbf{X}$ & & & $\mathbf{X}$ & & & & & & & $\mathbf{X}$ & & & $\mathbf{X}$ & & & & & & & $\mathbf{X}$ \\
\hline & Américas \#1 & $\mathbf{X}$ & & & & & & & $\mathbf{X}$ & & & $\mathbf{X}$ & & & & & & & $\mathbf{X}$ & & & $\mathbf{X}$ & & & & & & & & & $\bar{X}$ \\
\hline & Américas \#2 & & & $\mathbf{X}$ & & & & & $\mathbf{X}$ & & & & $\mathbf{X}$ & & & & & & $\mathbf{X}$ & & & & & & $\mathbf{X}$ & & & & & & $\mathbf{X}$ \\
\hline & Europa \#1 & & & $\mathbf{X}$ & & & & & & $\mathbf{X}$ & & & $X$ & & & & & $\mathbf{X}$ & & & & & & & $\mathbf{X}$ & & & & & $\mathbf{X}$ & \\
\hline & Europa \#2 & & & $X$ & & & & $\bar{X}$ & & & & & & $\mathbf{X}$ & & & & & $\mathbf{X}$ & & & & $\mathbf{X}$ & & & & & & $\mathbf{X}$ & & \\
\hline & Europa \#4 & & & & & & & $\mathbf{X}$ & & & & & & $\mathbf{X}$ & & & & $\mathbf{X}$ & & & & & & & & & & & & & \\
\hline & Europa \#5 & & & & $\bar{X}$ & & & & $\bar{X}$ & & & $\bar{X}$ & & & & & & $\mathrm{X}$ & & & & $\bar{X}$ & & & & & & & & $\mathbf{X}$ & \\
\hline & Europa \#7 & & & & & & & & & & & & & & & & & & & & & & & & & & & & & & \\
\hline
\end{tabular}

\begin{tabular}{|c|c|c|c|c|c|c|c|c|c|c|c|c|c|c|c|c|c|c|c|c|c|c|c|c|c|c|c|c|c|c|c|}
\hline \multirow{10}{*}{ 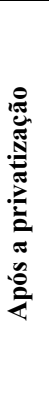 } & & \multicolumn{5}{|c|}{$\begin{array}{l}13 \text { - nível de } \\
\text { propaganda }\end{array}$} & \multicolumn{5}{|c|}{$\begin{array}{l}14 \text { - inovação em } \\
\text { processos de } \\
\text { produção }\end{array}$} & \multicolumn{5}{|c|}{$\begin{array}{c}15 \text { - busca } \\
\text { permanente por } \\
\text { redução de custos }\end{array}$} & \multicolumn{5}{|c|}{$\begin{array}{l}16 \text { - liderança } \\
\text { tecnológica }\end{array}$} & \multicolumn{5}{|c|}{$\begin{array}{l}17 \text { - mecanismos } \\
\text { de centralização e } \\
\text { coordenação }\end{array}$} & \multicolumn{5}{|c|}{$\begin{array}{c}18 \text { - relações com } \\
\text { o Governo }\end{array}$} \\
\hline & & 1 & 2 & 3 & 4 & 5 & 1 & 2 & 3 & 4 & 5 & 1 & 2 & 3 & 4 & 5 & 1 & 2 & 3 & 4 & 5 & 1 & 2 & 3 & 4 & 5 & 1 & 2 & 3 & 4 & 5 \\
\hline & África \#1 & & & $\bar{X}$ & & & & & & & $\bar{X}$ & & & & $\bar{X}$ & & & & & & $\bar{X}$ & & & $\mathbf{X}$ & & & & & & $\mathbf{X}$ & \\
\hline & Américas \#1 & & $\bar{X}$ & & & & & & & $\mathbf{X}$ & & & & $\mathbf{X}$ & & & & & & $\mathbf{X}$ & & & & & $\mathbf{X}$ & & & & $\mathbf{X}$ & & \\
\hline & Américas \#2 & & & $\mathbf{X}$ & & & & & & $\mathbf{X}$ & & & & & $\mathbf{X}$ & & & & $\mathbf{X}$ & & & & $\mathbf{X}$ & & & & & & & $\mathbf{X}$ & \\
\hline & Europa \#1 & & & & $\mathbf{X}$ & & & & $\mathbf{X}$ & & & & & $\mathbf{X}$ & & & & $\mathbf{X}$ & & & & & & & $\mathbf{X}$ & & & & & $\mathbf{X}$ & \\
\hline & Europa \#2 & & & & $\mathbf{X}$ & & & & & $\mathbf{X}$ & & & & & $\mathbf{X}$ & & & & & $\mathbf{X}$ & & & & & $\bar{X}$ & & & & $\mathbf{X}$ & & \\
\hline & Europa \#4 & & & & & & & & $\mathbf{X}$ & & & & & & & $\mathbf{X}$ & & & $\mathbf{X}$ & & & & & & & & & & & & \\
\hline & Europa \#5 & & $\mathbf{X}$ & & & & & & $\mathbf{X}$ & & & & & & $\mathbf{X}$ & & & & & $\mathbf{X}$ & & & & $\mathbf{X}$ & & & & $\mathbf{X}$ & & & \\
\hline & Europa \#7 & & & & & & & & & & & & & & & & & & & & & & & & & & & & & & \\
\hline
\end{tabular}

Ênfase em relação à média dos concorrentes:

$\mathbf{1}$ - muito menos $\mathbf{2}$ - menos $\quad \mathbf{3}$ - aproximadamente a mesma $\mathbf{4}$ - mais $\quad \mathbf{5}$ - muito mais 
ESTRATÉGIA - IMPACTOS DA PRIVATIZAÇÃO SOBRE AS ESTRATÉGIAS COMPETITIVAS DE EMPRESAS

DE PETRÓLEO: UM ESTUDO DE CASOS

JORGE MANOEL TEIXEIRA CARNEIRO - JORGE FERREIRA DA SILVA - MARIA ALICE D. FERREIRA CAVALCANTI

A empresa Américas \#1 se reposicionou no mercado especialmente através de oferta de produtos não-commodities, ampliação do nível de serviço (lojas de conveniência e centros de serviço), reforço da marca (em especial, através da modernização dos postos) melhoria da qualidade dos produtos e liderança tecnológica. Além disso procurou se aproximar dos concorrentes no que tange a desenvolvimento de novos produtos e controle sobre os canais de distribuição.

A empresa Américas \#2 vem buscando desenvolver uma estratégia de diferenciação, apoiada em identificação da marca (programa de fidelização do consumidor e novo visual dos postos), desenvolvimento de novos produtos e de produtos não-commodities, qualidade dos produtos e ampliação do nível de serviço (lojas de conveniência, fast food, lavagem de carro, troca de pneus e baterias).

A empresa Europa \#1 vem buscando melhorar sua posição de mercado através de aumento dos serviços agregados (ex.: financiamento às vendas), oferta de produtos complementares através de lojas de conveniência e reforço da marca (via aumento das despesas com propaganda e melhoria na identificação visual dos postos de serviço).

A empresa Europa \#2 baseou sua nova estratégia em quatro pontos principais: expansão das lojas de conveniência, financiamento às vendas, identificação de marca (pela aquisição de postos e a substituição do antigo logo pelo logo Europa \#2 e aumento no nível de propaganda) e aumento do controle sobre os canais de distribuição (especialmente pela ampliação do número de postos próprios). Vale notar que, mesmo antes da privatização, a Europa \#2 já havia desenvolvido uma estratégia de diferenciação baseada em nível de serviço, financiamento às vendas, identificação de marca e controle sobre os canais de distribuição.

A empresa Europa \#5 vem se reposicionando através oferta de opções de alimentação em seus postos de serviço, reforço da marca (via utilização discricionária de verba publicitária), oferta de produtos menos agressivos ao meio ambiente (com menor teor de enxofre e de aromáticos) e aumento da variedade de produtos, o que foi possível através da construção de uma planta de formulação e aditivação. À semelhança da Europa \#2, também a Europa \#5 já vinha praticando uma estratégia de diferenciação, mesmo antes da privatização, a qual também se baseava em nível de serviço, financiamento às vendas, identificação de marca e controle sobre os canais de distribuição.

Com relação ao fato de a maioria das empresas se situar no meio-termo antes da privatização, vale citar a opinião de Mahon \& Murray (1981), citados por Smith \& Grimm (1987), os quais argumentam que estratégias puras (focadas, na terminologia daqueles autores) não são tão importantes quando existe regulamentação econômica.

Em primeiro lugar, as ações e reações estratégicas não podem ser utilizadas livremente em ambiente regulados. A política de preços serve como exemplo: mesmo quando mudanças nos preços são aprovadas, sempre existe uma defasagem temporal até sua entrada em vigor e a informação se torna pública, retirando qualquer vantagem de uma possível manobra estratégica. Raciocínio similar se aplica às decisões sobre entrada e saída em segmentos de mercado, desenvolvimento de produtos e qualidade de produtos.

Em segundo lugar, ambientes regulamentados oferecem pouco espaço para recompensas por implementações bem sucedidas de estratégias competitivas. As entidades reguladoras procuram garantir um nível adequado, mas não excessivo, de lucros. Como resultado, uma empresa teria pouco incentivo para buscar uma estratégia de liderança em custos, pois os preços que ela seria autorizada a 
ESTRATÉGIA - IMPACTOS DA PRIVATIZAÇÃO SOBRE AS ESTRATÉGIAS COMPETITIVAS DE EMPRESAS

DE PETRÓLEO: UM ESTUDO DE CASOS

JORGE MANOEL TEIXEIRA CARNEIRO - JORGE FERREIRA DA SILVA - MARIA ALICE D. FERREIRA CAVALCANTI cobrar provavelmente seriam diminuídos de forma proporcional. De forma similar, uma empresa que busque a diferenciação talvez não seja autorizada a cobrar um preço-prêmio.

Adequabilidade e Aplicabilidade dos Modelos de Porter (1980) e de Mintzberg (1988)

A análise apresentada a seguir se baseia apenas nos casos de seis empresas que responderam integralmente à pesquisa.

Antes da privatização, a maioria das empresas não desenvolvia nenhuma estratégia consistente com os modelos de Porter e de Mintzberg. Como exceções a esta regra, vale citar os casos das empresas Europa \#2 e Europa \#5, ambas buscando desenvolver uma estratégia de diferenciação.

Após a privatização, as seis empresas enveredaram pela busca de uma estratégia de diferenciação, apoiada em diversos métodos competitivos. Todas as empresas procuraram adequar seu nível de custos, o que, conforme Porter $(1980,1985)$, é essencial para evitar que um provável aumento de custos advindo da diferenciação ultrapasse os benefícios de preço-prêmio ou aumento da parcela de mercado proporcionados por esta.

Antes da privatização, a tipologia de Mintzberg (1988) poderia ser útil no detalhamento das estratégias de duas empresas apenas: Europa \#2 e Europa \#5, ambas se utilizando basicamente de diferenciação por suporte e de diferenciação por imagem. As demais empresas não apresentavam qualquer estratégia consistente com o modelo de Mintzberg.

Após a privatização, cinco das seis empresas se utilizaram de uma diversidade de métodos competitivos relacionados a três ou mais tipos estratégicos de Mintzberg (1988), dentre as estratégias de diferenciação por qualidade, suporte, projeto e imagem. A empresa Europa \#1 é a única que se encaixaria em apenas dois tipos estratégicos: diferenciação por suporte e diferenciação por imagem (Tabela 4).

A empresa Europa \#3 não respondeu ao questionário alegando que seria difícil se classificar com relação a cada um dos métodos competitivos constantes do questionário, uma vez que a empresa atua com estratégias diferentes em diferentes segmentos. Este comentário levanta a questão: seria a tipologia proposta por Chrisman et al. (1988) mais apropriada que a tipologia de Porter (1980) ao entendimento das estratégias de empresas na indústria do petróleo?

Vale lembrar que a indústria de petróleo se caracteriza por ser de produção conjunta (ou seja, não é possível, por limitações físico-químicas e econômicas, produzir diesel sem produzir também, simultaneamente, gasolina e óleo combustível, entre outros produtos, assim como, na criação de gado, não é possível produzir filé mignon sem produzir simultaneamente chã e acém, mas apenas variar, dentro de certos limites, as proporções entre as diversas saídas), os pesquisadores assumiram, implicitamente, que as empresas empregariam a mesma estratégia para todos os produtos de seu portfólio. Isto poderia ter sido contornado caso se tivesse perguntado sobre a estratégia do principal (em termos de receita) produto da empresa. De qualquer forma, foi interessante verificar, ainda que não de forma deliberada, a existência deste tipo de posicionamento estratégico, mesmo porque alguns produtos atendem a segmentos e necessidades consideravelmente distintos dos de outros produtos 
Provavelmente, a tipologia de Chrisman et al. (1988) agregaria relevantes informações à classificação das estratégias destas empresas, uma vez que incorpora, explicitamente, a dimensão adicional de diversidade de vantagem competitiva por segmento. Esta tipologia se prestaria, portanto, à classificação, não apenas das estratégias por negócio/produto (estratégias competitivas) - que foram o foco da presente pesquisa - mas também à classificação das estratégias de gestão de portfólios de negócios/produtos (estratégia corporativa).

\section{Tabela 4 - Indicação das Estratégias Competitivas Adotadas pelas Empresas}

\begin{tabular}{|l|l|l|l|l|}
\hline \multicolumn{1}{|c|}{ Empresa } & \multicolumn{2}{|c|}{ Antes da Privatização } & \multicolumn{2}{c|}{ Após a Privatização } \\
\hline & $\begin{array}{c}\text { Tipologia de } \\
\text { Porter }\end{array}$ & $\begin{array}{c}\text { Tipologia de } \\
\text { Mintzberg }\end{array}$ & $\begin{array}{c}\text { Tipologia de } \\
\text { Porter }\end{array}$ & $\begin{array}{c}\text { Tipologia de } \\
\text { Mintzberg }\end{array}$ \\
\hline África \#1 & & & Diferenciação & $\begin{array}{l}\text { qualidade, projeto, } \\
\text { imagem }\end{array}$ \\
\hline Américas \#1 & & & Diferenciação & $\begin{array}{l}\text { qualidade, projeto, } \\
\text { suporte, imagem }\end{array}$ \\
\hline Américas \#2 & & Diferenciação & $\begin{array}{l}\text { Qualidade, projeto, } \\
\text { suporte, imagem }\end{array}$ \\
\hline Europa \#1 & & suporte, imagem & Diferenciação & Suporte, imagem \\
\hline Europa \#2 & diferenciação & suporte, imagem & Diferenciação & $\begin{array}{l}\text { Projeto, suporte, }, \\
\text { imagem }\end{array}$ \\
\hline Europa \#5 & diferenciação & &
\end{tabular}

A tipologia de Chrisman et al. (1988) incorpora também a possibilidade de uma empresa apresentar dois tipos simultâneos de vantagem competitiva (em um dado negócio/produto): baixo custo e diferenciação. Porter (1980, 1985), contudo, entende que esta posição não é sustentável no longo prazo (salvo em raras e temporárias circunstâncias especiais) e, portanto, não deveria ser considerada na tipologia. Esta posição de Porter tem sido criticada em diversos estudos teóricos (Faulkner \& Bowman, 1992, Hill, 1988, Wright, 1987 e Wright \& Parsinia, 1988) e empíricos (Dess \& Davis, 1984, Miller \& Dess, 1993 e White, 1986), que identificaram empresas bem sucedidas que se utilizavam simultaneamente das estratégias de diferenciação e de liderança em custo em um ou mais de seus segmentos-alvo de produto-mercado.

\section{CONCLUSÕES}

A pesquisa confirmou a ocorrência de significativas alterações nas posturas estratégicas das empresas de petróleo, o que é relevante tanto para os executivos destas empresas quanto os de outras empresas que ainda possam vir a passar por semelhantes processos de transformação no arcabouço regulatório de seus países. Ademais, sob o ponto de vista de legisladores e de agentes reguladores, é importante entender que o fato de as empresas terem optado por estratégias de diferenciação, inclusive enfatizando métodos competitivos nem sempre idênticos aos das demais empresas, reflete o fato de que há distintos segmentos de consumidores que valorizam determinados conjuntos de atributos (em termos de características de produto, serviços, conveniência, reputação de marca, etc.) distintamente de outros segmentos de consumidores e estariam dispostos a pagar mais caro para terem suas preferencias especificas melhor atendidas. Em vista disso, os legisladores e agentes reguladores poderiam, então, imprimir maior flexibilidade aos processos de autorizações para lançamento de novos produtos e de definição de preços de produtos que excedam as especificações básicas de funcionalidade e 
ESTRATÉGIA - IMPACTOS DA PRIVATIZAÇÃO SOBRE AS ESTRATÉGIAS COMPETITIVAS DE EMPRESAS

DE PETRÓLEO: UM ESTUDO DE CASOS

JORGE MANOEL TEIXEIRA CARNEIRO - JORGE FERREIRA DA SILVA - MARIA ALICE D. FERREIRA CAVALCANTI

desempenho (ou seja, os produtos não precisariam ser padronizados nem os preços, uniformes), enquanto manteriam rigidez no tocante a controle de poluentes, adulteracao de produtos e evasão fiscal.

De uma forma geral, a tipologia de Porter (1980) se mostrou adequada à classificação das estratégias das empresas. Assim, pode-se dizer que este estudo vem contribuir para a validação externa do modelo de Porter, uma vez que a maioria das pesquisas utilizando o modelo de Porter tem se baseado fortemente numa economia desenvolvida, como também em indústrias maduras ou em declínio (Kim \& Lim, 1988) - ambiente diverso daquele das empresas do presente estudo, as quais atravessaram uma fase de ruptura e transição decorrentes da desregulamentação. A validação, ainda que de forma simplificada, de modelos de classificação de estratégias genéricas em outros contextos é importante para fornecer o necessário referencial de análise a executivos, legisladores e agentes reguladores.

A presente pesquisa sugere, ainda, que a tipologia de Mintzberg 1988) seria também adequada ao entendimento das estratégias pós-privatização das empresas pesquisadas, apesar do fato de estas, por empregarem métodos competitivos diversos, não se enquadrarem de forma unívoca em nenhum dos tipos estratégicos de Mintzberg, ou seja, estas empresas apresentariam uma multiplicidade de tipos estratégicos. Por outro lado, vale ressaltar que diversos pesquisadores da área de Administração Estratégica têm sugerido que os tipos estratégicos não são necessariamente mutuamente exclusivos (Hill, 1988 e Wright, 1987, dentre outros já citados anteriormente), sendo, portanto, possível a observação de superposições de mais de um tipo estratégico em uma mesma empresa, sem que isto signifique desempenho inferior. Pode-se, ainda, conjeturar que a estratégia de diferenciação, tal como proposta por Porter (1980) seria implementada através da ênfase, não apenas em um, mas em diversos métodos competitivos (ex.: qualidade de produto, inovação em produto, imagem de marca, nível de serviços, política de preço, etc.), os quais se reforçariam mutuamente para atingir o objetivo estratégico. A tipologia de Mintzberg ofereceria maior poder descritivo, por não ser tão agregada, mas perderia em parcimônia e capacidade de mapeamento unívoco, o que, contudo, não lhe retira a característica de ser uma tipologia facilmente aplicável à prática gerencial.

Vale ressaltar que a escolha metodológica da presente pesquisa pode ter influenciado nas respostas aos questionários e na própria interpretação dos resultados por parte dos pesquisadores. É possível que, tanto os respondentes quanto os pesquisadores, tenham, ainda que não deliberadamente, se esforçado para classificar as empresas de acordo com as definições e prescrições de um determinado modelo estratégico que vem sendo disseminado na prática corporativa e acadêmica ao longo das últimas duas décadas. Além disso, conforme Mir \& Watson (2000), o papel do investigador na construção do modelo de pesquisa e na interpretação dos resultados em pesquisas de Administração Estratégica (assim como em outras práticas sociais) é de fundamental importância e pode afetar as conclusões. É importante notar, contudo, que não se observaram incoerências ou dificuldades, dentro das regras de classificação adotadas, para enquadramento das estratégias das empresas segundo os tipos estratégicos de cada um dos modelos investigados. Caso eventuais incoerências ou dificuldades tivessem ocorrido, isto poderia indicar a inadequabilidade de um dos (ou ambos os) modelos ou sugerir que um fosse mais adequado que o outro.

Com relação à tipologia sugerida por Chrisman et al. (1988), que contem 14 tipos estratégicos, resta ainda a questão de se determinar se o maior poder explanatório que ela poderia proporcionar compensaria a perda de parcimônia com relação às tipologias propostas por Porter e Mintzberg.

Por fim, uma vez que não foi realizado um tratamento estatístico sobre os dados (a amostra é muito pequena), os resultados devem ser interpretados com cautela, pois não há como se removerem outliers ou se identificarem padrões desviados. 


\section{SUGESTÕES PARA ESTUDOS FUTUROS}

Embora o modelo de Porter (1980) seja um dos modelos de estratégias mais utilizados em pesquisas empíricas, grande parte destas pesquisas tem se limitado a setores econômicos nos Estados Unidos. Há muito a ganhar, portanto, se outros pesquisadores testarem o modelo em países com economias significativamente distintas.

Em complemento ao estudo de Kotha \& Vadlamani (1995), a discussão sobre o poder explanatório da tipologia de Porter (1980), em comparação com outras tipologias alternativas — Mintzberg (1988), Chrisman et al. (1988) e Miller \& Dess (1993), por exemplo — também merece ser melhor investigada. (Por razões de limitação de espaço, as tipologias de Chrisman et al., 1988, e de Miller \& Dess, 1993, não foram apresentadas neste artigo, mas sua referência está relacionada na bibliografia.)

Uma contribuição importante às pesquisas na área seria o estabelecimento de um conjunto parcimonioso de métodos competitivos, a partir dos vários diferentes métodos distintos que vêm sendo empregados por diferentes pesquisadores. O estabelecimento de um conjunto básico permitiria uma melhor comparação entre os resultados das diversas pesquisas e muito contribuiria para a validação e generalização de modelos.

Futuros estudos poderão também detalhar o ambiente competitivo através da análise individual de cada um dos elementos da estrutura da indústria (Porter, 1980), ou seja, dos componentes de cada uma das cinco forças, em vez de utilizar simplesmente uma análise agregada de cada força.

\section{BIBLIOGRAFIA}

BONOMA, Thomas V., Case Research in Marketing: Opportunities, Problems and a Process, Journal of Marketing Research, v.22 May p.199-208, 1985

CAVALCANTI, Maria Alice F. Deschamps, Impactos Estratégicos e Organizacionais Decorrentes da Desregulamentação do Setor Petrolífero Argentino: Estudo de Caso da Yacimientos Petrolíferos Fiscales (YPF), dissertação de Mestrado não publicada, Departamento de Administração, Pontifícia Universidade Católica do Rio de Janeiro, 1997

CHRISMAN, James J., HOFER, Charles W., BOULTON, William R., Toward a System for Classifying Business Strategies, Journal Academy of Management Review, v.13 n.3, p.413-428, 1988

CONANT, Jeffrey S., MOKWA, Michael P., VARADARAJAN, P. Rajan, Strategic Types, Distinctive Marketing Competencies and Organizational Performance: A Multiple Measures-Based Study, Strategic Management Journal, v.11 n.5 Sept p.365-383, 1990

DESS, Gregory G. \& DAVIS, Peter S., Porter's (1980) Generic Strategies as Determinants of Strategic Group Membership and Organizational Performance, Academy of Management Journal, v.27 n.3 Sept p.467-488, 1984 
ESTRATÉGIA - IMPACTOS DA PRIVATIZAÇÃO SOBRE AS ESTRATÉGIAS COMPETITIVAS DE EMPRESAS DE PETRÓLEO: UM ESTUDO DE CASOS

JORGE MANOEL TEIXEIRA CARNEIRO - JORGE FERREIRA DA SILVA - MARIA ALICE D. FERREIRA CAVALCANTI

FAULKNER, David \& BOWMAN, Cliff, Generic Strategies and Congruent Organisational Structures: Some Suggestions, European Management Journal, v.10 n.4 p.494-499, Dec. 1992

GOLDEN, Brian. R., The Past Is the Past - Or Is It? The Use of Retrospective Accounts as Indicators of Past Strategy, Academy of Management Journal, v.35 p.848-860, 1992

HAMBRICK, Donald C., An Empirical Typology of Mature Industrial-Product Environments, Academy of Management Journal, v.26 n.2, p.213-230, 1983b

, Some Tests of the Effectiveness and Functional Attributes of Miles and Snow's Strategic Types, Academy of Management Journal, v.26 n.1, p.5-26, 1983a

HARRIGAN, Kathryn Rudie, Research Methodologies for Contingency Approaches to Business Strategy, Academy of Management Review, v.8 n.3 p.398-405, July 1983

HERBERT, Theodore T. \& DERESKY, Helen, Generic Strategies: An Empirical Investigation of Typology and Strategy Content, Strategic Management Journal, v.8 p.135-147, 1987

HILL, Charles W. L. \& DEEDS, David L., The Importance of Industry Structure for the Determination of the Firm Profitability: A Neo-Austrian Perspective, Journal of Management Studies, v.33 n.4 p.429-451 July, 1996

, Differentiation Versus Low Cost or Differentiation and Low Cost: A Contingency Framework, Academy of Management Review,v.13 n.3 p.401-412, July 1988

HUBER, George P. \& POWER, Daniel J., Retrospective Reports of Strategic-Level Managers: Guidelines for Increasing their Accuracy, Strategic Management Journal, v.6 p.171-180, 1985

HUNT, Shelby D. \& MORGAN, Robert M., The Comparative Advantage Theory of Competition, Journal of Marketing, v.59 April p.1-15, 1995

KIM, Linsu \& LIM, Yooncheol, Environment, Generic Strategies and Performance in a Rapidly Changing Country: A Taxonomic Approach, Academy of Management Journal, v.31 p.802-827, 1988

KOTHA, Suresh \& VADLAMANI, Bhatt L., Assessing Generic Strategies: An Empirical Investigation of Two Competing Typologies in Discrete Manufacturing Industries, Strategic Management Journal, v.16 p.75-83, 1995

MAHON, J. F. \& MURRAY, E. A., Strategic Planning for Regulated Companies, Strategic Management Journal, p.251-262, Apr-Jun 1981

MILES, Raymond E. \& SNOW, Charles C., MEYER, Alan D., COLEMAN, Jr. Henry J., Organizational Strategy, Structure, and Process, Academy of Management Review, v.3 n.3 July p.546-562, 1978

MILLER, A. \& DESS, Gregory G., Assessing Porter's (1980) Model in Terms of Its Generability, Accuracy and Simplicity, Journal of Management Studies, v.30 n.4 p.553-585, Jul 1993 
MINTZBERG, Henry, Generic Strategies: Toward a Comprehensive Framework, Advances in Strategic Management, v.5 JAI Press Greenwich - CT p.1-67, 1988

MIR, Raza \& WATSON, Andrew, Strategic Management and the Philosophy of Science: The Case for a Constructivist Methodology, Strategic Management Journal, v.21, p.941-953, 2000

PORTER, Michael E., Competitive Advantage: Creating and Sustaining Competitive Performance, New York: The Free Press, 1985

, Competitive Strategy: Techniques for Analyzing Industries and Competitors, New York: The Free Press, 1980

RODRIGUES, Gisele M. S., Integração Vertical e Inovações Organizacionais: O Caso da Petróleos de Venezuela S.A. (PDVSA), dissertação de Mestrado não publicada, IEI - Universidade Federal do Rio de Janeiro, 1995

SMITH Ken G. \& GRIMM, Curtis M., Environmental Variation, Strategic Change and Firm Performance: A Study of Railroad Deregulation, Strategic Management Journal, v.8p.363-376, 1987

SNOW, Charles C. \& HAMBRICK, Donald C., Measuring Organizational Strategies: Some Theoretical and Methodological Problems, Academy of Management Review, v.5 n.4 p.527-538, 1980

WHITE, Roderick E., Generic Business Strategies, Organizational Context and Performance: An Empirical Investigation, Strategic Management Journal, v. 7, p.217-231, 1986

WRIGHT, Peter, A Refinement of Porter's Strategies, Strategic Management Journal, v.8 p.93-101, 1987

\& PARSINIA, Alex, Porter's Synthesis of Generic Business Strategies: A Critique, Industrial Management, v.30, n. 3, p.20-23, May-Jun 1988 